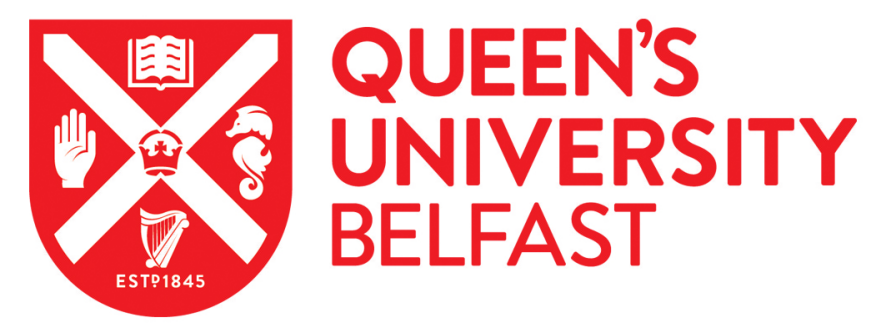

\title{
Experimental validation of a drive-by stiffness identification method for bridge monitoring
}

McGetrick, P. J., Kim, C-W., González, A., \& Brien, E. J. O. (2015). Experimental validation of a drive-by stiffness identification method for bridge monitoring. Structural Health Monitoring, 14(4), 317-331. https://doi.org/10.1177/1475921715578314

\section{Published in:}

Structural Health Monitoring

\section{Document Version:}

Peer reviewed version

Queen's University Belfast - Research Portal:

Link to publication record in Queen's University Belfast Research Portal

Publisher rights

(c) 2015 The Author(s)

\section{General rights}

Copyright for the publications made accessible via the Queen's University Belfast Research Portal is retained by the author(s) and / or other copyright owners and it is a condition of accessing these publications that users recognise and abide by the legal requirements associated with these rights.

Take down policy

The Research Portal is Queen's institutional repository that provides access to Queen's research output. Every effort has been made to ensure that content in the Research Portal does not infringe any person's rights, or applicable UK laws. If you discover content in the Research Portal that you believe breaches copyright or violates any law, please contact openaccess@qub.ac.uk. 


\title{
Experimental validation of a drive-by stiffness identification method for bridge monitoring
}

\author{
P.J. McGetrick ${ }^{1 *}$, C.W. Kim² ${ }^{2}$ A. González ${ }^{3} \&$ E.J. OBrien ${ }^{3}$ \\ ${ }^{1}$ School of Planning, Architecture and Civil Engineering, Queen's University Belfast, David Keir \\ Building, Belfast BT9 5AG, UK \\ ${ }^{2}$ Department of Civil and Earth Resources Engineering, Kyoto University, Kyoto 615-8540, Japan \\ ${ }^{3}$ School of Civil, Structural \& Environmental Engineering, University College Dublin, Newstead, Belfield, \\ Dublin 4, Ireland
}

Corresponding author $(*)$ :

Email: p.mcgetrick@qub.ac.uk

Phone: +44-28-9097-5456

Fax: $\quad+44-28-9097-4278$

\section{Abstract}

An experimental investigation is carried out to verify the feasibility of using an instrumented vehicle to detect and monitor bridge dynamic parameters. The low cost method consists of the use of a moving vehicle fitted with accelerometers on its axles. In the laboratory experiment, the vehicle-bridge interaction model consists of a scaled two-axle vehicle model crossing a simply supported steel beam. The bridge model also includes a scaled road surface profile. The effects of varying the vehicle model configuration and speed are investigated. A finite element beam model is calibrated using the experimental results and a novel algorithm for the identification of global bridge stiffness is validated. Using measured vehicle accelerations as input to the algorithm, the beam stiffness is identified with a reasonable degree of accuracy.

\section{Keywords}

Acceleration, bridge, drive-by, monitoring, stiffness, vehicle-bridge interaction. 


\section{Introduction}

The maintenance of bridge structures in a transport network is essential in order to ensure safety, in addition to providing cost effective operation of the network. The need to assess and maintain the condition of bridge structures has influenced a considerable amount of research in the area of structural health monitoring (SHM) in recent years. ${ }^{1-3,4}$ Increasingly, bridges are being instrumented for the purposes of vibration based monitoring, which in general focuses on modal parameters such as frequency and mode shapes. A number of authors ${ }^{5-7}$ provide comprehensive reviews of vibration based damage identification and condition monitoring methods in the literature. However, the requirement for direct instrumentation of the bridge to enable monitoring can be a downside as it has implications related to time and cost, such as operational downtime, labour required for manual installation of multiple sensors and/or data acquisition equipment on the bridge and associated maintenance costs for these installations.

This paper presents a laboratory experimental validation of an alternative method for the vibration based assessment of bridges. The proposed method is low cost and consists of the analysis of the dynamic response of a vehicle as it passes over a bridge, also referred to in the literature as an indirect monitoring approach $^{8,9}$. The vehicle is fitted with accelerometers to its axles, reducing the need for any direct installation of equipment on the bridge itself. As all of the data acquisition electronics are also contained within the vehicle which can travel at highway speeds, it allows for a so called drive-by bridge inspection system, enabling widespread preliminary assessment of existing bridge structures' conditions without the need to stop the vehicle.

The feasibility of extracting bridge dynamic parameters such as natural frequency from the dynamic response of an instrumented vehicle has been verified theoretically. ${ }^{10-13}$ Yang et al. ${ }^{10}$ find that the magnitude of the peak response in the vehicle acceleration spectra increased with vehicle speed but 
decreases with increasing bridge damping ratio. In a study by McGetrick et al. ${ }^{12}$ the bridge frequency and changes in bridge damping are extracted from the vehicle response but they find that it is difficult to detect both parameters in the presence of a rough road profile. Also, frequency matching between the vehicle and the bridge is highlighted by both Yang et al. ${ }^{10}$ and González et al. ${ }^{13}$ as being beneficial for frequency detection. Yang and Chang ${ }^{14}$ also carry out a parametric study which indicates some of the best conditions for frequency detection.

Drive-by inspection has also been tested in field trials and it has been found that accurate determination of the bridge natural frequency is feasible for low speeds and sufficiently high dynamic excitation of the bridge due to the influence of road roughness on the vehicle response. ${ }^{15-18}$ Yang and Chang ${ }^{18}$ make use of the empirical mode decomposition technique to identify the frequencies of higher modes from the vehicle response.

Experimental investigations have been conducted to check the feasibility of the approach as part of a drive-by inspection system for bridge monitoring. Toshinami et al. ${ }^{19}$ extract the bridge frequency from the response of a passing vehicle in a laboratory experiment. Kim and Kawatani ${ }^{20}$ investigate a condition screening and damage detection approach which uses an inspection car for data acquisition from wireless sensor nodes installed on the bridge. The inspection car also acts as an actuator to the bridge. It is found that the approach can identify the location and severity of damage via analysis and comparison of the stiffness distribution throughout the bridge between intact and damaged states. Bu et al. ${ }^{21}$ also present a numerical investigation of a bridge condition assessment technique which focuses on the stiffness. Their approach utilises the dynamic response of a vehicle moving along a Euler-Bernoulli beam to detect damage in terms of stiffness reduction. They find that vehicle speed, measurement noise, road surface roughness and model errors do not have a significant effect on the accuracy of the damage detection. 
In this paper, the aim is to experimentally validate a novel stiffness identification algorithm at laboratory scale, which uses the measured acceleration responses of the vehicle as the input. In the laboratory, a scaled vehicle-bridge model is used consisting of a scaled two-axle vehicle and a simply supported steel beam, which incorporates a scaled road surface profile. For the purposes of a complete analysis, a coupled Vehicle Bridge Interaction (VBI) simulation model is created in MATLAB ${ }^{22}$ and calibrated using the experimental data.

\section{Experimental setup}

\section{Bridge model}

The scaled bridge model used in the experiment is a $5.4 \mathrm{~m}$ simply supported steel beam (Figure 1). The simple support conditions are shown in Figure 2. The beam is fitted with accelerometers and displacement transducers at quarter span, mid-span and three-quarter span to monitor its response in free vibration tests and during vehicle crossings. The beam properties obtained from the manufacturer and free vibration tests are given in Table 1. The frequency and damping of the beam were calculated as the mean of five repeated free vibration tests. The product of the beam's modulus of elasticity, $E$ and second moment of area, $J$, i.e., the global beam stiffness, $E J$, is found by calibration in this study.

The bridge model also incorporates a scaled road surface profile which the vehicle model travels along, shown in Figure 3. Only one profile was investigated and this was scaled based on a measured road profile from a $40.4 \mathrm{~m}$ roadway bridge studied by Kim et al. ${ }^{23}$. The measured profile is categorised as very good (Class A) according to $\mathrm{ISO}^{24}$. Therefore, the scaled profile is intended to be representative of that expected on a typical highway bridge. However, some discrepancies with the measured profile exist due to the idealisation of the scaled profile as a superposition of steps formed by a simple construction method using layered tape and plastic strips. This material was selected to avoid unexpected noise in the 
measured signal during the moving vehicle experiment, which could be caused by interaction between the vehicle's plastic wheels and the steel track. For this particular profile, the effect of some of the larger irregularities on the vehicle results in a subsequent increase in the excitation of the bridge. It follows that the bridge's influence on the vehicle response also increases; this factor can sometimes be beneficial for indirect approaches and the type of identification algorithm investigated in this paper ${ }^{25}$.

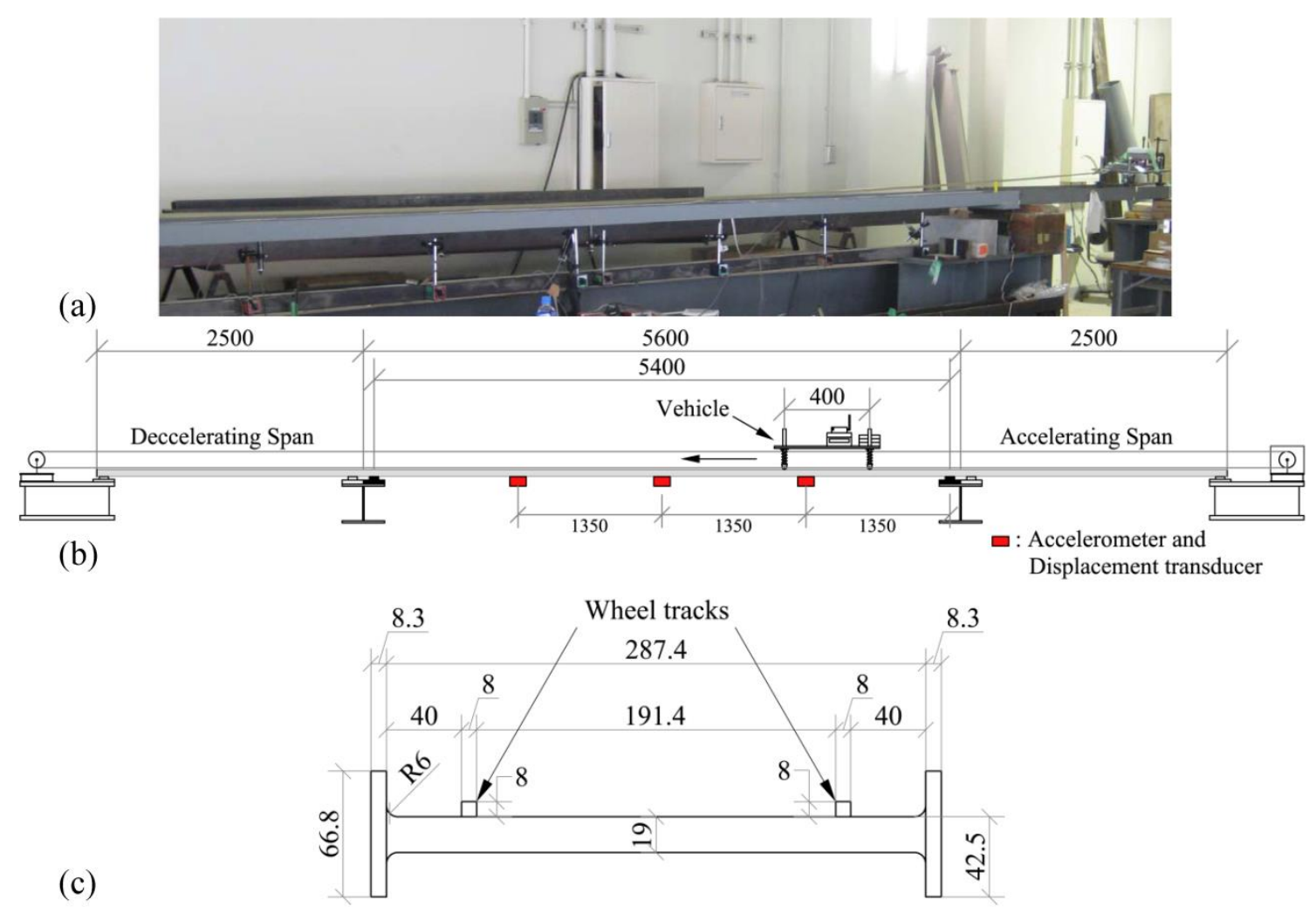

Figure 1. Experimental Beam; (a) Laboratory setup (b) Elevation of setup (c) Beam cross-section (units in $\mathrm{mm}$ ). 


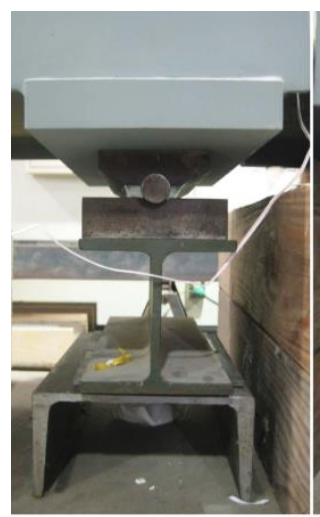

(a)

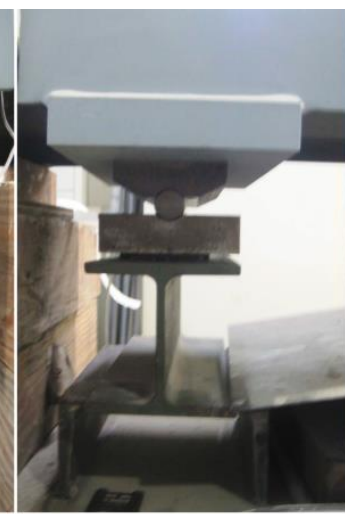

(b)

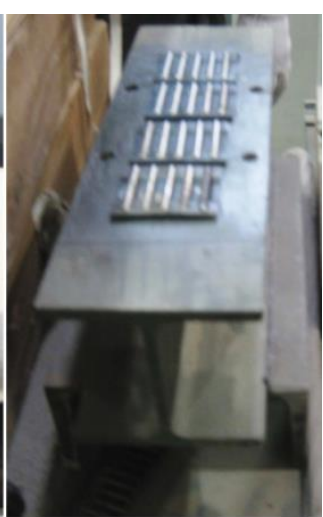

(c)

Figure 2. Simple support conditions of beam (a) pinned support (b) roller support (c) rollers.

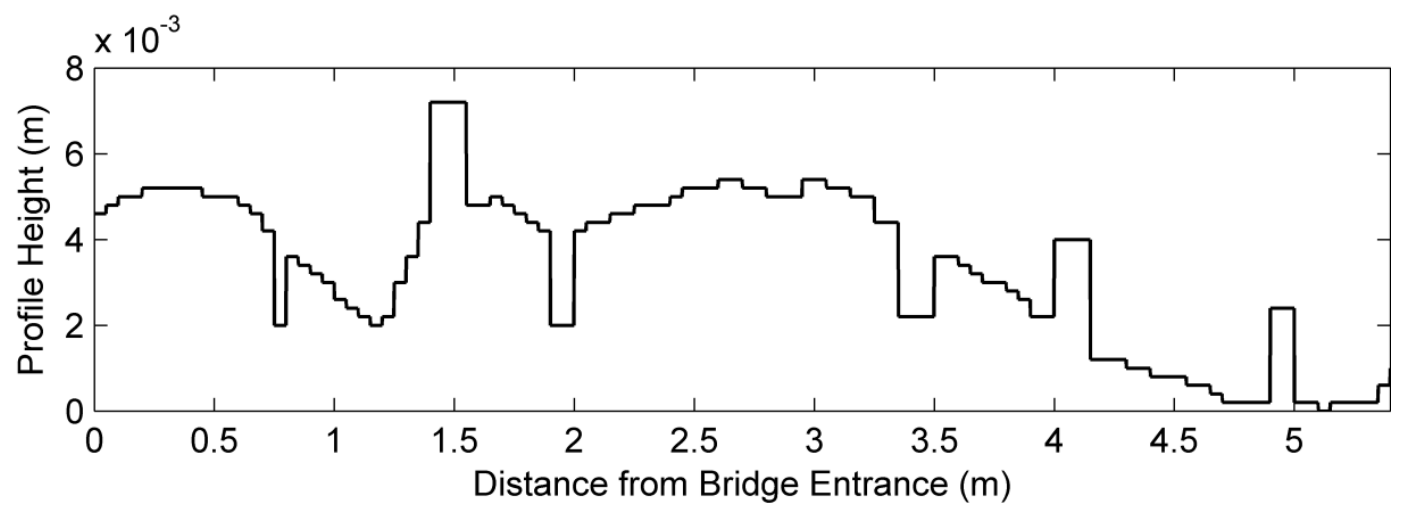

Figure 3. Experimental road profile.

Table 1. Bridge model properties.

\begin{tabular}{lllll}
\hline $\begin{array}{l}\text { Span Length, } \\
L(\mathrm{~m})\end{array}$ & $\begin{array}{l}\text { Material density, } \\
w\left(\mathrm{~kg} / \mathrm{m}^{3}\right)\end{array}$ & $\begin{array}{l}\text { Cross sectional area, } \\
A\left(\mathrm{~m}^{2}\right)\end{array}$ & $\begin{array}{l}\text { First natural frequency, } \\
f_{b, 1}(\mathrm{~Hz})\end{array}$ & $\begin{array}{l}\text { Damping } \\
\text { Ratio, } \xi\end{array}$ \\
\hline 5.4 & 6800 & $6.7 \times 10^{-3}$ & 2.69 & 0.016 \\
\hline
\end{tabular}




\section{Vehicle Model}

A scaled two-axle vehicle model is instrumented for the experiments (Figure 4). It is fitted with 2 accelerometers to monitor the vehicle bounce motion; these are located at the centre of the front and rear axles respectively. It also includes a wireless router and data recorder which allow the acceleration data to be recorded remotely. The vehicle model can be adjusted to obtain different axle configurations and dynamic properties; the spring stiffness of the axles can be varied by changing the springs while the body mass can be varied using steel plates. The properties of the three vehicle model configurations chosen for these experiments are given in Table 2, which were determined prior to testing. The axle masses were obtained using weighing scales. The suspension spring stiffness was provided by the spring manufacturer and the suspension damping was established as the mean of five repeated free vibration tests using the logarithmic decrement technique. ${ }^{26}$ The axle spacing and track width for all models were $0.4 \mathrm{~m}$ and $0.2 \mathrm{~m}$ respectively. The vehicle/bridge mass ratios were $7.6 \%$ for both vehicles V1 and V2 and $9.2 \%$ for V3, which were relatively high but are similar to those expected in practice for a typical 18 tonne two-axle truck on a short span bridge.

The vehicle was propelled by a motor and pulley system (Figure 5)and its speed was maintained constant by an electronic controller as it crossed the bridge. An approach length was provided before and after the bridge span to allow for acceleration and deceleration. The entry and exit of the vehicle to the beam was monitored using strain sensors in order to synchronise measurements; entry and exit points appeared as peaks in the strain signals. The scaled vehicle speeds adopted for the experiment are $0.46 \mathrm{~m} / \mathrm{s}, 0.93 \mathrm{~m} / \mathrm{s}$ and $1.63 \mathrm{~m} / \mathrm{s}$ represented by $\mathrm{S} 1, \mathrm{~S} 2$ and $\mathrm{S} 3$ respectively. $\mathrm{S} 1$ to $\mathrm{S} 3$ give dimensionless speed parameters $(\gamma)$ of $0.016,0.032$ and 0.056 respectively using equation (1). ${ }^{27}$ They are similar to speed parameters of $0.015,0.029$ and 0.059 estimated using speeds of $10 \mathrm{~km} / \mathrm{h}, 20 \mathrm{~km} / \mathrm{h}$ and $40 \mathrm{~km} / \mathrm{h}$ respectively for an existing $40.4 \mathrm{~m}$ bridge span with first bending mode of $2.35 \mathrm{~Hz}$. 


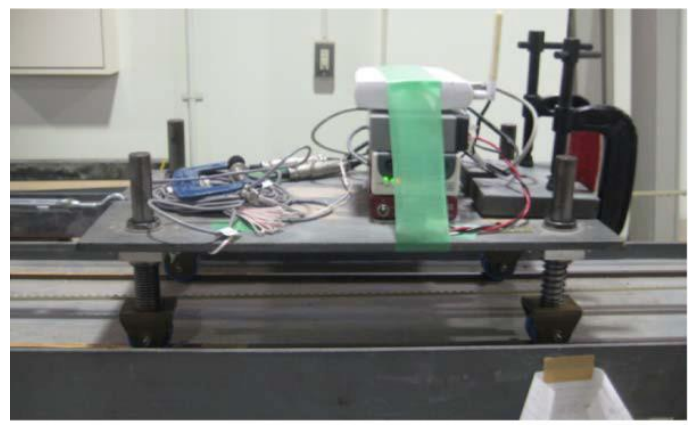

(a)

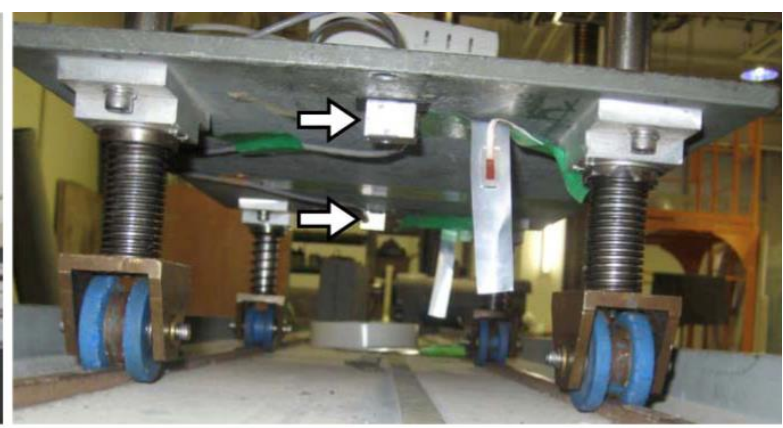

(b)

Figure 4. Experimental vehicle; (a) side view (b) end view showing accelerometer locations (arrows).

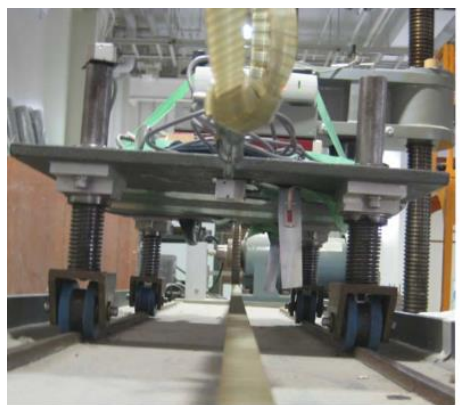

(a)

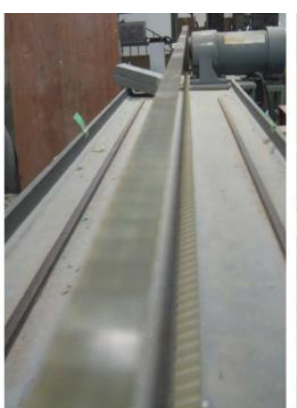

(b)

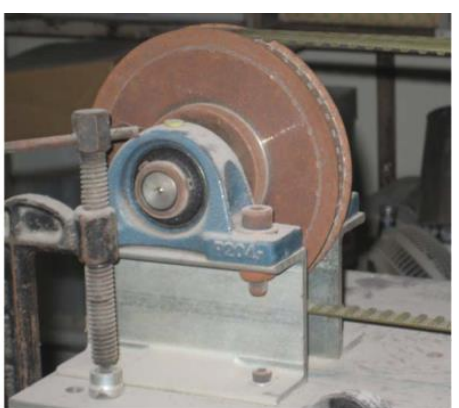

(c)

Figure 5. Vehicle propulsion system (a) vehicle connection (b) motor and belt (c) pulley wheel.

Table 2. Vehicle model properties.

\begin{tabular}{lllllll}
\hline Vehicle & Mass (kg) & & $\begin{array}{l}\text { Suspension stiffness } \\
(\mathrm{N} / \mathrm{m})\end{array}$ & \multicolumn{2}{c}{$\begin{array}{l}\text { Suspension damping } \\
(\mathrm{N} \mathrm{s} / \mathrm{m})\end{array}$} \\
\hline & Axle 1 & Axle 2 & Axle 1 & Axle 2 & Axle 1 & Axle 2 \\
\hline V1 & 7.9 & 13.445 & 2680 & 4570 & 16.006 & 27.762 \\
\hline V2 & 7.9 & 13.445 & 4290 & 7310 & 13.991 & 35.112 \\
\hline V3 & 8.355 & 17.530 & 2700 & 5940 & 18.023 & 65.829 \\
\hline
\end{tabular}




$$
\gamma=\frac{c}{2 f_{b, 1} L}
$$

In equation (1), $\gamma$ is the speed parameter, $c$ is the vehicle speed $(\mathrm{m} / \mathrm{s}), f_{b, 1}$ is the first natural frequency of the bridge $(\mathrm{Hz})$ and $L$ is the bridge span length $(\mathrm{m})$. This dimensionless parameter is important for the scaling of the experimental model as it is used to maintain a relationship between vehicle speed, frequency and span length for the $5.4 \mathrm{~m}$ beam which is similar to that for a $40.4 \mathrm{~m}$ bridge subject to real traffic. $^{23}$

\section{Sensors and data acquisition electronics}

The accelerometers used for the bridge and vehicle were KYOWA AS-1GBZ1 small-capacity acceleration transducers with rated capacities of $\pm 9.807 \mathrm{~m} / \mathrm{s}^{2}( \pm 1 \mathrm{~g})$. The displacement transducers used for the bridge were CDP-25 transducers by Tokyo Sokki Kenkyjo Co. Ltd (TML) with $25 \mathrm{~mm}$ capacity, spring force of $3.4 \mathrm{~N}$ and sensitivity of $5 \times 10^{-6} \mathrm{strain} / \mathrm{mm}$. Three DC-104R dynamic strain recorder units by TML, fitted with BA104 battery packs, were used for data acquisition and power supply; two units for bridge sensors and one for the vehicle (Figure 4). These units stored all data on compact flash memory cards. DC-7630 Dynamic Strain Recorder measurement software by TML was used for monitoring, collection and processing of measured data from the recorders. Data recorded on the unit fitted to vehicle was monitored remotely during crossings via a wireless LAN connection; the recorder was connected to a SX-2500CG wireless Ethernet adapter by Silex Technology for this purpose (Figure 4). It should be noted that a scanning frequency of $100 \mathrm{~Hz}$ was used by the data acquisition system for all experiments. 


\section{Outline of experimental procedures}

The aim of the laboratory experiment is to verify that the global bridge stiffness can be extracted from the vehicle response. Therefore, a series of experiments are developed for this purpose and they are outlined briefly in this section.

Vehicle crossing measurements. Beam and vehicle accelerations and beam displacements are recorded during vehicle crossings for all vehicle models and speeds. The displacement measurements are used for the calibration of the VBI simulation model while the vehicle accelerations are used as input to the stiffness identification algorithm. An example of the vehicle accelerations obtained from a crossing for vehicle V1 and speed S2 is illustrated in Figure 6(a). By processing these accelerations using a fast Fourier transform (FFT) and plotting the corresponding power spectral density (PSD), Figure 6(b) is obtained. The spectral resolution is $\pm 0.098 \mathrm{~Hz}$ here.
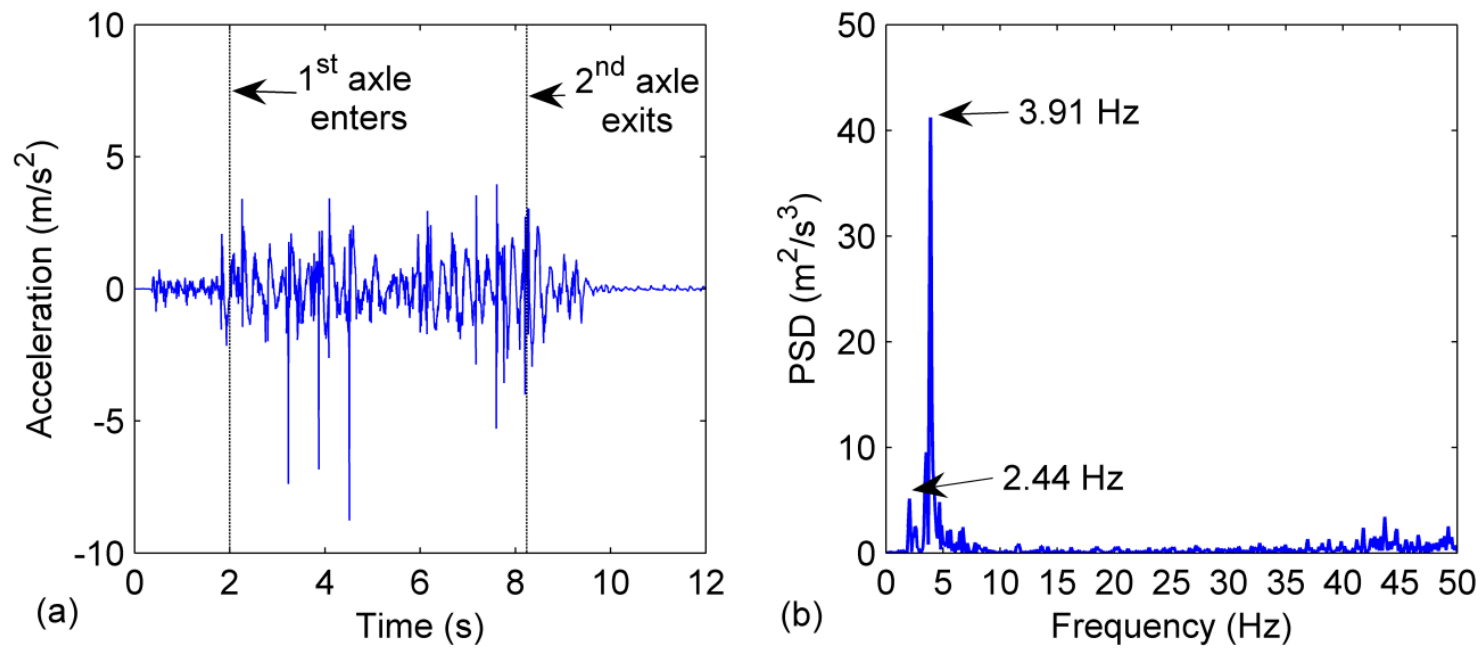

Figure 6. Vehicle 1 and Speed 2 (V1S2) (a) axle 1 accelerations (b) spectrum of axle 1 accelerations. 
It can be seen from Figure 6(b) that axle 1 of the vehicle vibrates predominantly at its pitch frequency ( $3.91 \mathrm{~Hz}$ ). It is found that the dynamic response of axle 2 (not shown here) is much less sensitive to the sprung mass pitch rotation of the vehicle as it has a higher axle weight than axle 1. However, a peak corresponding to the bridge natural frequency is also present at $2.44 \mathrm{~Hz}$ in Figure 6(b). This is lower than the frequency obtained from free vibration tests $(2.69 \mathrm{~Hz})$. Although the resolution of the spectrum is poorer here than that obtained in free vibration tests $( \pm 0.048 \mathrm{~Hz})$ due to the shorter signal length here, the frequency shift is too large for this to be the cause of the decrease. The decrease can be attributed to the coupling of the vehicle and beam during the crossing as the mass of the system increases; a number of researchers have observed and acknowledged similar trends ${ }^{28,29}$. Such variations are accounted for in the time-varying theoretical model via the coupling of the vehicle and bridge.

\section{Calibration of theoretical vehicle-bridge interaction model}

To allow for a comprehensive analysis of the experimental results, a VBI simulation model is created in MATLAB. The properties of the beam and vehicle used in this VBI model are those given in Table 1 and Table 2 respectively. To minimise error due to modelling approximations, an FE model updating procedure $^{30,31}$ is used which minimises the differences between simulated and experimental data in an optimisation problem. This type of procedure has been employed in the analysis of beam and bridge structures, examples of which can be found in the literature. ${ }^{32-34}$ Here, the Cross-Entropy (CE) method of optimisation $^{35}$ is used to calibrate the global beam stiffness, EJ, in the theoretical VBI model. The objective function used to evaluate the performance of each candidate stiffness in the optimisation is defined as the sum of the squared differences between the simulated and measured displacement responses of the beam. 


\section{Coupled vehicle-bridge interaction model}

The VBI is modelled as a coupled system (Figure 7) with the solution given at each time step using the Wilson-Theta direct integration scheme. Similar models incorporating the coupling of the vehicle and bridge have been employed in the literature ${ }^{23,36-38}$ and a review of these and other models has been carried out by González. ${ }^{39}$

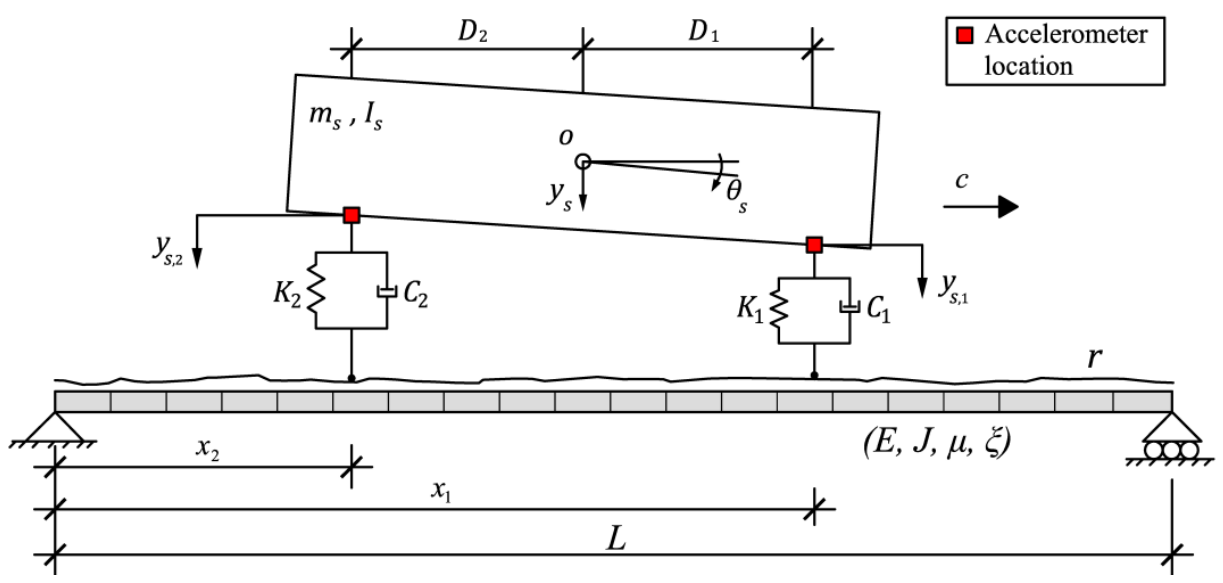

Figure 7. Coupled vehicle-bridge interaction model.

Vehicle model. The vehicle model in the coupled system is represented by a 2 degree of freedom (DOF) half-car which crosses the bridge model at constant speed $c$ (Figure 7). It is a simplified vehicle model but it is sufficient to model the important aspects of the response of the experimental vehicle. The configuration of the two DOF model can be defined by coordinates $y_{s}$ and $\theta_{s}$, the sprung mass bounce displacement, and pitch rotation respectively. The vehicle body and axle component masses are represented by the sprung mass, $m_{s}$. A combination of springs of linear stiffness $K_{i}$ and viscous dampers with damping coefficient $C_{i}$ represent the suspension components for the front and rear axles $(i=1,2)$. 
Also, $I_{s}$ is the sprung mass moment of inertia and the distance of each axle to the vehicle's centre of gravity $(o)$ is given by $D_{1}$ and $D_{2}$.

The equations of motion of the vehicle are obtained by imposing equilibrium of all forces and moments acting on the vehicle and expressing them in terms of the coordinates

$$
\begin{gathered}
m_{s} \ddot{y}_{s}+F_{t, 1}+F_{t, 2}=0 \\
I_{s} \ddot{\theta}_{s}+D_{1} F_{t, 1}-D_{2} F_{t, 2}=0
\end{gathered}
$$

where $F_{t, i}$ is the dynamic interaction force between the vehicle and bridge at wheel $i$

$$
F_{t, i}=K_{i}\left(y_{s}-(-1)^{i} D_{i} \theta_{s}-w_{v, i}\right)+C_{i}\left(\dot{y}_{s}-(-1)^{i} D_{i} \dot{\theta}_{s}-\dot{w}_{v, i}\right) ; i=1,2
$$

where $w_{v, i}$ is the total displacement under wheel $i$. This parameter can be defined in terms of the road profile elevation and bridge displacement under wheel $i: r_{i}$ and $w_{b, i}$ respectively as

$$
w_{v, i}=w_{b, i}+r_{i} ; \quad i=1,2
$$

The experimental road profile heights $r_{i}$ are used for this model (Figure 3). Due to the stepped nature of the profile, difficulties can be anticipated in the theoretical model relating to the interaction force transmitted via the vehicle dashpots (Figure 7) as infinite velocities can occur. However, in reality, infinite velocities are avoided as the vehicle wheels do not experience point contact but contact over a portion of the wheel surface. Therefore, to avoid infinite velocities in the model, the wheel contact patch 
of the vehicle in the experiment is simulated by applying a moving average filter to the profile heights over a distance of $0.006 \mathrm{~m}$, which corresponds to one-fifth of the diameter of the wheel. As sprung mass acceleration measurements are recorded above the suspension of each axle in the experiment (Figure 4(b)), the relationship between the coordinates of the vehicle and the measurements is defined by the following equation

$$
\ddot{y}_{s, i}=\ddot{y}_{s}-(-1)^{i} D_{i} \ddot{\theta}_{s} ; i=1,2
$$

The vehicle system defined by equations (2) and (3) can also be written for the purpose of coupling with the bridge model as

$$
\mathbf{M}_{v} \ddot{\mathbf{y}}_{v}+\mathbf{C}_{\mathrm{v}} \dot{\mathbf{y}}_{\mathrm{v}}+\mathbf{K}_{\mathrm{v}} \mathbf{y}_{\mathbf{v}}=\mathbf{f}_{\mathrm{v}}
$$

where $\mathbf{M}_{\mathbf{v}}, \mathbf{C}_{\mathbf{v}}$, and $\mathbf{K}_{\mathbf{v}}$ are, respectively, the mass, damping and stiffness matrices of the vehicle while $\mathbf{f}_{\mathbf{v}}$ is the time varying force vector applied to the vehicle and $\mathbf{y}_{\mathbf{v}}=\left\{y_{s}, \theta_{s}\right\}^{\mathrm{T}}$ is the displacement vector of the vehicle. Expressions for these matrices and vectors are given in Appendix 1.

The experimental properties given in Table 2 for the three vehicle models are used in conjunction with $\mathbf{M}_{\mathbf{v}}$ and $\mathbf{K}_{\mathbf{v}}$ to carry out modal analysis on the theoretical model. The frequencies obtained from this analysis are given in Table 3. The mean frequencies obtained from vehicle acceleration spectra of five free vibration tests for each experimental vehicle model are also given in Table 3 for comparison; the standard deviations of the five free vibration tests are given in parentheses. The theoretical bounce frequencies match those of the experimental model very well. The pitch frequencies do not provide quite as good a match. This can be attributed to differences between the mathematical (2-D) and real physical 
models e.g. the pulley system, and measurement errors derived from the dominance of the body bounce frequency in free vibration tests which reduces the visibility of the identified pitch frequency peak in the vehicle acceleration spectrum. Such errors may reduce the accuracy of the stiffness identification algorithm thus the positive results presented in this paper indicate the strength of the algorithm.

Table 3. Vehicle model frequencies from modal analysis.

\begin{tabular}{lllll}
\hline \multirow{2}{*}{ Vehicle } & \multicolumn{2}{l}{ Body Bounce $(\mathrm{Hz})$} & \multicolumn{2}{l}{ Body Pitch $(\mathrm{Hz})$} \\
\cline { 2 - 5 } & Theoretical & Experiment Mean & Theoretical & Experiment Mean \\
\hline V1 & 2.93 & $2.93( \pm 0)$ & 3.92 & $4.24( \pm 0.11)$ \\
\hline V2 & 3.71 & $3.62( \pm 0)$ & 4.96 & $5.35( \pm 0.22)$ \\
\hline V3 & 2.91 & $2.91( \pm 0)$ & 3.72 & $3.62( \pm 0.20)$ \\
\hline
\end{tabular}

Bridge model. The bridge is represented by a simply supported FE beam model (Figure 7) of total span length $L$. It consists of 8 discretised beam elements with 4 degrees of freedom which have constant mass per unit length, $\mu$, modulus of elasticity $E$ and second moment of area $J$. However, to maintain continuity of displacement and slope between elements, neighbouring beam elements have common displacement and rotation at shared nodes. In addition, boundary conditions are applied by constraining the nodal displacement to zero at each end node. Thus, the beam has 16 degrees of freedom in total. The response of the beam model to a series of moving time-varying forces is given by the system of equations

$$
\mathbf{M}_{\mathbf{b}} \ddot{\mathbf{w}}_{\mathbf{b}}+\mathbf{C}_{\mathbf{b}} \dot{\mathbf{w}}_{\mathbf{b}}+\mathbf{K}_{\mathbf{b}} \mathbf{w}_{\mathbf{b}}=\mathbf{N}_{\mathbf{b}} \mathbf{f}_{\text {int }}
$$

where $\mathbf{M}_{\mathbf{b}}, \mathbf{C}_{\mathbf{b}}$ and $\mathbf{K}_{\mathbf{b}}$ are $(n \times n)$ global mass, damping and stiffness matrices of the beam model respectively, $\mathbf{w}_{\mathbf{b}}, \dot{\mathbf{w}}_{\mathbf{b}}$ and $\ddot{\mathbf{w}}_{\mathbf{b}}$ are the $(n \times 1)$ global vectors of nodal bridge displacements and rotations, 
their velocities and accelerations respectively, and $\mathbf{N}_{\mathbf{b}} \mathbf{f}_{\mathbf{i n t}}$ is the $(n \times 1)$ global vector of forces applied to the bridge nodes. Here, the parameter $n=18$; this consists ofthe total number of degrees of freedom of the bridge (16) plus the two constrained nodal displacements at each end of the beam. The total interaction force between the vehicle and the bridge is described using the $\left(n_{f} \times 1\right)$ vector

$$
\mathbf{f}_{\text {int }}=\left\{\begin{array}{l}
P_{1}+F_{t, 1} \\
P_{2}+F_{t, 2}
\end{array}\right\}
$$

where $P_{i}$ is the static load of axle $i . \mathbf{N}_{\mathbf{b}}$ is an $\left(n \times n_{f}\right)$ location matrix that distributes the $n_{f}$ applied interaction forces on beam elements to equivalent forces acting on the nodes; for this half-car model, $n_{f}=$ 2. The details of this matrix are given in Appendix 1. This location matrix can be used to calculate the bridge displacement under each wheel, $w_{b, i}$, in equation (5) using

$$
\left\{\begin{array}{l}
w_{b, 1} \\
w_{b, 2}
\end{array}\right\}=\mathbf{N}_{\mathbf{b}}{ }^{\mathrm{T}} \mathbf{w}_{\mathbf{b}}
$$

Damping ratios of the experimental bridge calculated from free vibration tests were similar for the first two modes thus considering these modes ${ }^{40}$ Rayleigh damping is adopted here to model the damping of the experimental beam using

$$
\mathbf{C}_{\mathbf{b}}=\alpha \mathbf{M}_{\mathbf{b}}+\beta \mathbf{K}_{\mathbf{b}}
$$

where $\alpha$ and $\beta$ are constants. The damping ratio $\xi$ is assumed to be the same for the first two modes and $\alpha$ and $\beta$ are obtained from $\alpha=2 \xi \omega_{1} \omega_{2} /\left(\omega_{1}+\omega_{2}\right)$ and $\beta=2 \xi /\left(\omega_{1}+\omega_{2}\right)$ where $\omega_{1}$ and $\omega_{2}$ are the first two natural frequencies of the bridge. ${ }^{26}$ 
Coupling of the vehicle - bridge interaction system. The vehicle and bridge systems are coupled at the contact point of the wheel via the interaction force $\mathbf{f}_{\text {int }}$. Equations (7) and (8) are combined to form the coupled system of equations as

$$
M_{g} \ddot{\mathbf{u}}+\mathbf{C}_{\mathrm{g}} \dot{\mathbf{u}}+\mathbf{K}_{\mathrm{g}} \mathbf{u}=\mathbf{f}
$$

where $\mathbf{M}_{\mathbf{g}}$ is the combined system mass matrix, $\mathbf{C}_{\mathbf{g}}$ and $\mathbf{K}_{\mathbf{g}}$ are coupled time-varying system damping and stiffness matrices respectively and $\mathbf{f}$ is the system force vector (see Appendix 1). Also, $\mathbf{u}=\left\{\mathbf{y}_{\mathbf{v}}, \mathbf{w}_{\mathbf{b}}\right\}^{\mathbf{T}}$ is the displacement vector of the system. Equation (12) is solved using the Wilson-Theta integration scheme $^{41,42}$ using the optimal value of the parameter $\theta=1.42$ (correct to 3 significant figures) for unconditional stability. ${ }^{43}$

\section{Calibration using Cross Entropy Optimisation}

As the vehicle model has been calibrated prior to experimental testing, the focus of the calibration presented here is on the properties of the prismatic beam, specifically its stiffness, $E J\left(\mathrm{~N} \mathrm{~m}^{2}\right)$. The value provided by the manufacturer is $E J_{\text {design }}=115,400 \mathrm{~N} \mathrm{~m}^{2}$. However, due to the installation of displacement transducers to take measurements, it is expected that the apparent or effective stiffness of the beam during the experiment will be higher as the CDP-25 transducers provide some resistance to displacement. It must also be noted that there can be a difference between the static modulus of elasticity (obtained from static tests) and dynamic modulus of elasticity (obtained from dynamic or free vibration tests). Previous research has shown that a structure may react with a higher modulus to a dynamic load than to a static one. These differences have been found to be up to $20 \%$ and higher in bridge structures. ${ }^{44}$ Therefore it is necessary to calibrate the theoretical model to take account of this increase. ${ }^{30}$ 
The CE method of optimisation ${ }^{35}$ has been implemented by Walsh and González ${ }^{45}$ to determine the stiffness distribution throughout a FE beam model from its response to a static load. The CE method is an optimisation approach which employs Monte Carlo simulation to generate populations of trial solutions which converge to a single optimal solution. The process involves two main stages; (1) Generation of a random sample of data (e.g. in this paper, candidate stiffness values) and (2) Updating of the mechanism of random data generation to produce an improved sample in the next generation. An advantage of this approach is its relative ease of implementation while it is insensitive to local optima. ${ }^{46,47}$

In this paper, the approach of Walsh and González ${ }^{45}$ is adapted to determine the global stiffness value for the FE beam model which gives the best fit between theoretical static and measured quasi-static beam displacements. Hence, the optimisation problem is formulated as a least squares minimisation of the difference, over $N_{j}$ time steps, between these displacements at quarter span, mid-span and three-quarter span of the beam. The objective function is given below in equation (13), where $t_{j}$ is the jth time step and $x_{k}$ is the $k$ th measurement location on the beam. The theoretical static displacement responses of the beam, $w_{\text {static,sim }}$, are simulated by solving the coupled system described by equation (12) with the mass and damping matrices set to zero. A low pass filter is applied to the measured displacements at $1 \mathrm{~Hz}$ to obtain the measured quasi-static responses, $w_{\text {static,obs. }}$. The CE method is used to obtain the optimal global beam stiffness values for all vehicle models and speeds investigated in the experiment. A constant stiffness distribution throughout the beam is assumed.

$O(E J)=\sum_{k=1}^{3} \sum_{j=1}^{N_{j}}\left(w_{\text {static }, \text { obs }}\left(x_{k}, t_{j}\right)-w_{\text {static, sim }}\left(x_{k}, t_{j}, E J\right)\right)^{2}$ 
The results of the optimisation for all vehicles and speeds are given in Table 4. These values are used for the calibrated beam in simulations using the coupled VBI model. On average, these values exceed the design stiffness, $E J_{\text {design }}$, by approximately $17 \%$. The standard deviation of these values is approximately $1 \%$ of the mean. Table 4 also shows that the optimal stiffness value decreases with increasing vehicle speed. Although this variation is small, it can be attributed to two related factors; vehicle speed and the length of time the vehicle is on the beam. For different vehicle speeds, unfiltered dynamic effects in measured responses between 0-1 Hz vary and influence this decrease. At higher speeds, the vehicle is on the beam for a shorter length of time. This in turn decreases the length of time within which the displacement transducers can influence the beam displacement. This effect manifests itself as a slight decrease in stiffness with increasing speed. The optimal stiffness value also varies depending on the vehicle model used, illustrating the importance of calibrating the theoretical model for all variations of this experimental setup.

Table 4. Results of CE method for calibration of beam stiffness.

\begin{tabular}{llll}
\hline \multicolumn{4}{l}{ Optimal Stiffness Values $\times 10^{5}\left(\mathrm{~N} \mathrm{~m}^{2}\right)$} \\
\hline Vehicle & Speed & \\
\hline & $\mathrm{S} 1$ & $\mathrm{~S} 2$ & $\mathrm{~S} 3$ \\
\hline $\mathrm{V} 1$ & 1.370 & 1.343 & 1.336 \\
\hline $\mathrm{V} 2$ & 1.359 & 1.350 & 1.341 \\
\hline $\mathrm{V} 3$ & 1.374 & 1.364 & 1.356 \\
\hline
\end{tabular}




\section{Drive-by Stiffness Identification}

The experimental investigation includes the validation of a novel algorithm which aims to identify the stiffness of a bridge from vehicle acceleration measurements. In this section, the global beam stiffness is found from vehicle acceleration signals only, without recourse to the bridge responses used in the calibration of the VBI model. The idealisation of the experimental vehicle as a two degree of freedom system in the coupled VBI model with both degrees of freedom measured results in a well-conditioned problem. Therefore, elements of a similar algorithm employed by González et al. ${ }^{25}$ for the purpose of bridge damping identification are incorporated to take account of this idealisation. The details of the algorithm are summarised briefly here. The target bridge stiffness values to be identified by the algorithm in the experiment are those found by calibration and given in Table 4.

The stiffness identification algorithm involves a sequential procedure comprising of six main steps and these are outlined in Figure 8. The measured vehicle accelerations from the experiment are used as input to the algorithm. Firstly, the acceleration vector $\ddot{\mathbf{y}}_{\mathbf{v}}$ of equation (7) is obtained by converting the acceleration measurements $\ddot{y}_{s, i}$ for axle $i(=1,2)$ to sprung mass bounce $\ddot{\theta}_{s}$ and pitch accelerations $\ddot{y}_{S}$ using equation (6). The velocity and displacement vectors of equation (7), $\dot{\mathbf{y}}_{\mathbf{v}}=\left\{\dot{y}_{s}, \dot{\theta}_{s}\right\}^{\mathrm{T}}$ and $\mathbf{y}_{\mathbf{v}}=$ $\left\{y_{s}, \theta_{s}\right\}^{\mathrm{T}}$ respectively, are obtained by integrating the accelerations with respect to time.

The second step involves calculating the vector of total contact forces, $\mathbf{f}_{\mathbf{i n t}}$. Equations (2) and (3), which relate to equation (7), are solved as a pair of simultaneous equations to obtain the dynamic forces $F_{t, i}$ while the static loads $P_{i}$ are known from prior measurement, allowing $\mathbf{f}_{\mathbf{i n t}}$ to be established from equation (9). The total displacements under each wheel, $w_{v, i}$, are calculated in the third step by solving equation (4) as a 1st order differential equation in $w_{v, i}$ using the Runge-Kutta method. A linear correction is applied to the displacements $w_{v, i}$ to minimise any low frequency drift error arising from the integration 
of accelerations. The correction technique employed is described by González et al. ${ }^{25}$ and is based on the true bridge displacement being zero at the entrance and the exit to the bridge, i.e., at $0 \mathrm{~m}$ and $5.4 \mathrm{~m}$ respectively.

In the fourth step, the total contact forces, $\mathbf{f}_{\mathbf{i n t}}$, obtained in the second step, are applied directly to the FE beam model described earlier (Figure 7). An initial estimate of the stiffness, $E J_{\text {est }}$, is given to the beam to obtain the displacement vector $\mathbf{w}_{\mathbf{b}}$ due to the moving loads in $\mathbf{f}_{\text {int }}$ (equation (8)). Then, the displacement response of the beam, $w_{b, i}$, under each force is calculated using equation (10). This process is repeated for stiffness estimates ranging from $1 \times 10^{3}$ to $9 \times 10^{8} \mathrm{~N} \mathrm{~m}^{2}$ in steps of 0.1 . These estimates can be represented by $\left(a \times 10^{b}\right) \mathrm{N} \mathrm{m}^{2}$ where $a$ ranges from 1 to 9 in steps of 0.1 . As Table 4 shows that the 'true' stiffness values fall between $1.3 \times 10^{5} \mathrm{~N} \mathrm{~m}^{2}$ and $1.4 \times 10^{5} \mathrm{~N} \mathrm{~m}^{2}$, the step is reduced to 0.01 between these values for $a$. The power $b$ ranges from 3 to 8 in steps of 1 . This gives a total of 540 stiffness estimates for the beam, which in turn provides 540 estimates of $w_{b, i}$ for wheel $i$.

In the fifth step, equation (5) is rearranged to obtain road profile height estimates, $r_{e s t, i}$, under each wheel by subtracting $w_{b, i}$ (step 4) from the total displacements $w_{v, i}$ (step 3) giving

$$
r_{e s t, i}=w_{v, i}-w_{b, i} ; \quad i=1,2
$$

Here, a band pass filter (with lower and upper cut-off frequencies of 2 and $10 \mathrm{~Hz}$ respectively) is also applied to the profile estimates, $r_{e s t, i}$. This removes bridge static displacements which, after linear correction, still suffer from accumulated errors due a large integration drift. Importantly, the use of this band pass filter to remove low frequency errors does not affect the algorithm accuracy as the vibration of the first mode of the bridge, related to its stiffness, remains. 
The bridge stiffness is identified in the final sixth step. As the wheels follow each other along the same wheel path, the profile estimates under each wheel $\left(r_{e s t, 1}\right.$ and $\left.r_{e s t, 2}\right)$ should be equal for the correct stiffness value. A least squares error minimisation process is used to identify the optimal stiffness value from the range of estimates investigated. It consists of a summation over all measurements in time, $t$. The optimal solution is identified as the stiffness estimate which provides the minimum least squares error between the profile estimates under each wheel (equation (15)).

$$
r_{\text {error }}=\sum_{t}\left(r_{e s t, 1}-r_{e s t, 2}\right)^{2}
$$




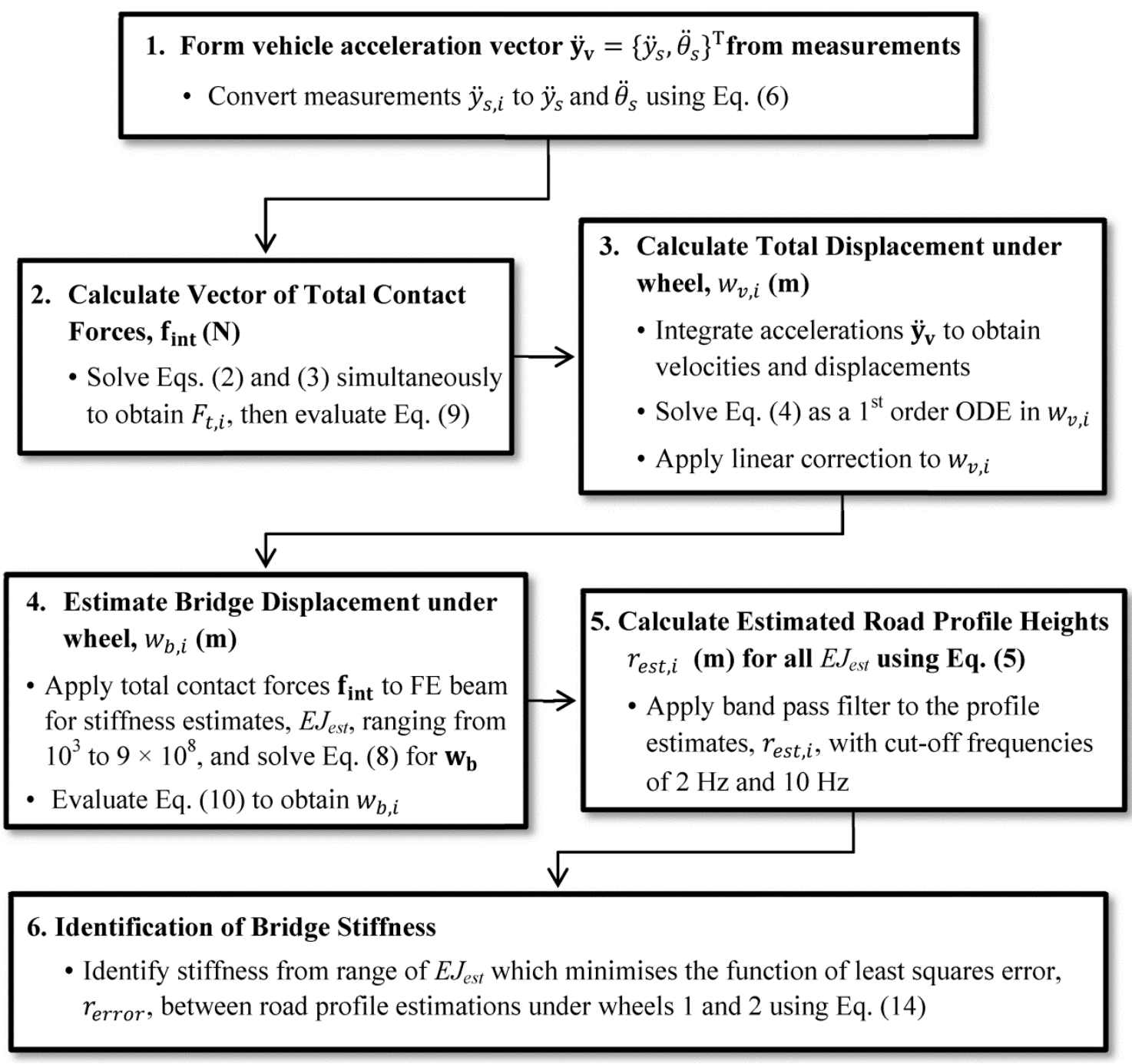

Figure 8. Bridge stiffness identification algorithm

\section{Results and discussion}

Figure 9 shows the least squares error between profile estimates under the wheels $\left(r_{e s t, i}\right)$ (equation (15)) for vehicle V1 and speed S1, on a log-log scale. The minimum error can be seen to occur as a local minimum in the region of the true stiffness value. Figure 10(a) and (c) show the total measured axle 
contact forces for vehicle V1 and speed S2 which are used in the algorithm. The corresponding forces predicted by the coupled VBI model are also plotted while the frequency spectra of all forces are included in Figure 10(b) and (d) for comparison and show that there is a reasonable match between them.

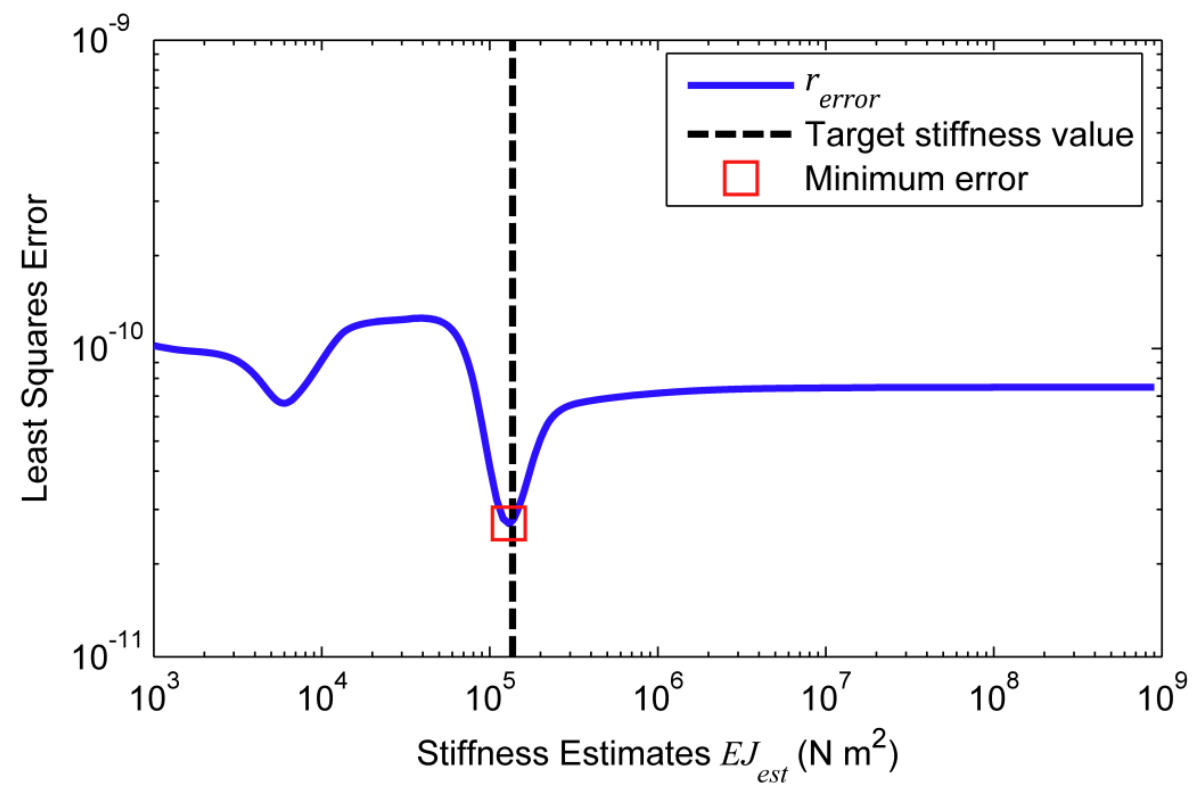

Figure 9. Least squares error, $r_{\text {error }}$, versus global stiffness estimates $\left(E J_{e s t}\right)$ for $\mathrm{V} 1$ and $\mathrm{S} 1$. Target stiffness value is $1.37 \times 10^{5} \mathrm{~N} \mathrm{~m}^{2}$. 

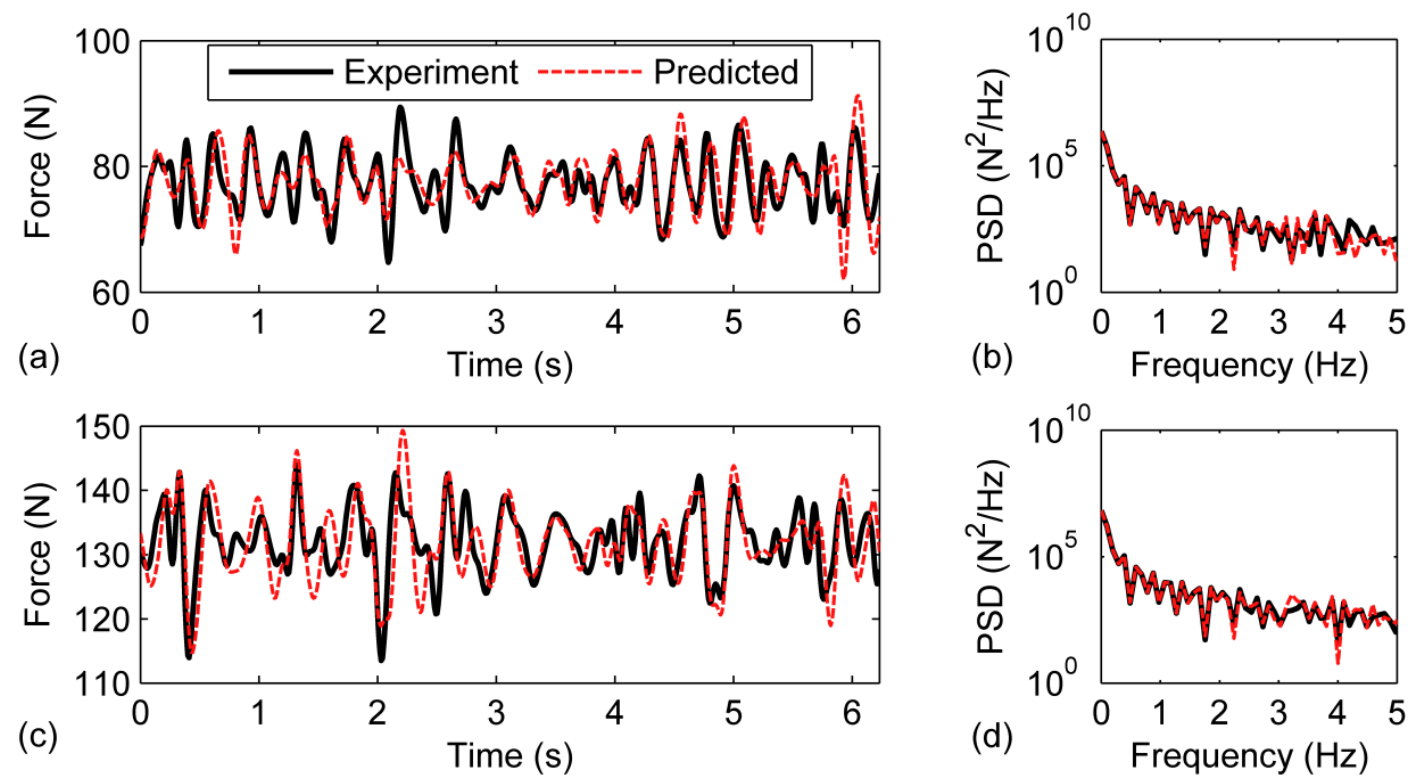

Figure 10. Contact forces $\mathbf{f}_{\text {int }}$ and their spectra calculated from experiment and predicted using coupled VBI model for vehicle V1 and speed S2. (a) Axle 1 forces (b) Axle 1 force spectrum (c) Axle 2 forces (d) Axle 2 force spectrum.

Table 5 shows the identified global stiffness values from the algorithm for all vehicles and speeds tested. The percentage errors are given in Table 6, corresponding to the error between the identified stiffness values and those obtained from calibration in Table 4. For each case, the crossings are repeated five times to test the repeatability of the method with the mean values given in Table 5 . The standard deviations of the identified values from the five tests are also given in Table 6 as percentages of the mean values. The results show that the algorithm detects the correct stiffness value accurately; within 5\% error for vehicles V2 and V3 at all speeds and for vehicle V1 at speeds S1 and S2. The test for vehicle V1 and speed S3 gives the least accurate prediction with an error of $7.2 \%$. Aside from this case, the algorithm is not very sensitive to the selection of speed. A strength of this algorithm is its repeatability, which can be seen from Table 6, with the average standard deviation being $5.22 \%$. 
Table 5. Identified bridge stiffness values.

\begin{tabular}{llll}
\hline \multicolumn{4}{l}{ Beam Stiffness, $E J_{\text {identified }}, \times 10^{5}\left(\mathrm{~N} \mathrm{~m}^{2}\right)$} \\
\hline Vehicle & Speed & \\
\hline & $\mathrm{S} 1$ & $\mathrm{~S} 2$ & $\mathrm{~S} 3$ \\
\hline $\mathrm{V} 1$ & 1.314 & 1.342 & 1.240 \\
\hline $\mathrm{V} 2$ & 1.382 & 1.284 & 1.312 \\
\hline $\mathrm{V} 3$ & 1.406 & 1.408 & 1.306 \\
\hline
\end{tabular}

Table 6. Percentage errors and standard deviations of identified stiffness values.

\begin{tabular}{|c|c|c|c|c|c|c|}
\hline \multirow{3}{*}{ Vehicle } & \multicolumn{3}{|c|}{ Percentage Error $(\%)$} & \multicolumn{3}{|c|}{ Standard deviation $(\%)$} \\
\hline & \multicolumn{6}{|l|}{ Speed } \\
\hline & $\mathrm{S} 1$ & $\mathrm{~S} 2$ & S3 & $\mathrm{S} 1$ & $\mathrm{~S} 2$ & S3 \\
\hline V1 & -4.10 & -0.07 & -7.20 & 1.15 & 3.96 & 7.21 \\
\hline $\mathrm{V} 2$ & 1.69 & -4.89 & -2.16 & 9.20 & 6.27 & 5.56 \\
\hline V3 & 2.33 & 3.23 & -3.69 & 4.31 & 4.09 & 5.24 \\
\hline
\end{tabular}

Overall, these are promising results illustrating the potential of implementing the stiffness identification algorithm as part of a drive-by bridge inspection system. In practice, the accuracy of the algorithm will depend on the existence of an FE model of the bridge and vehicle. It follows that model calibration forms an important part of this approach. Also, although vehicle speed has been highlighted in the literature as being important for the detection of bridge dynamic parameters from the vehicle response, it is not a critical parameter when estimating bridge stiffness using this algorithm. 
It is also important to note that the experiment was operated under controlled conditions in a laboratory; it was not exposed to changes in environmental or operational effects such as temperature, humidity, wind and other traffic loads. In reality at full scale, stiffness-related bridge frequency variations due to such effects are typically observed to be of the order of 5-10\% but can exceed this, while damage may cause relatively smaller variations ${ }^{48-51}$. Therefore, although the percentage errors observed for the experimental results are quite low in this paper, the conditions under which this algorithm could be implemented for damage detection may be limited in practice by environmental and operational factors, such as traffic and temperature in particular. As this method is aimed at short to medium span bridges, the probability of other traffic on the bridge can be small. However, in general it may be necessary to incorporate models which remove or reduce the influence of these factors ${ }^{3,48,52}$.

\section{Conclusions}

This paper presents the laboratory experimental validation of an algorithm for the identification of global bridge stiffness from a vehicle response. For the purpose of the validation, a coupled vehicle-bridge interaction model is calibrated using the Cross-Entropy method of optimisation. The calibrated stiffness of the beam is found to be higher than the value provided by the manufacturer.

Using the experimental data, it is found that for 8 of the 9 vehicle-speed combinations, the algorithm identifies the correct value of stiffness within a 5\% margin of error while the average standard deviation of the stiffness estimates is $5.2 \%$. In practice, the repeatability of the method and its insensitivity to speed are advantages. It is also acknowledged that in practice, preliminary calibration of an FE model of the bridge will be required and environmental and operational effects will need to be considered. 
The results experimentally verify the feasibility of identifying the bridge stiffness from the acceleration measurements of a moving vehicle for the scenarios investigated. Although a number of difficulties are likely to arise in the field due to modelling inaccuracies, the results of this validation suggest that an instrumented vehicle has the potential to be implemented as a low cost method for the periodic monitoring of the stiffness of short to medium span bridges as part of a drive-by inspection system.

\section{Acknowledgments}

The authors wish to express their gratitude and appreciation to Prof. M. Kawatani and Mr. T. Toshinami for their support and assistance during this experimental investigation.

\section{Funding}

This research was supported by the Japanese Society for the Promotion of Science Postdoctoral Fellowship for North American and European Researchers (Short Term); the $7^{\text {th }}$ European Framework ASSET (Advanced Safety and Driver Support in Efficient Road Transport) project; and the Japanese Society for the Promotion of Science Grant-in-Aid for Scientific Research (B) [Project No. 24360178].

\section{Appendix 1}

$$
\begin{aligned}
& \mathbf{M}_{\mathbf{v}}=\left[\begin{array}{cc}
m_{s} & 0 \\
0 & I_{s}
\end{array}\right] \\
& \mathbf{C}_{\mathbf{v}}=\left[\begin{array}{cc}
C_{1}+C_{2} & D_{1} C_{1}-D_{2} C_{2} \\
D_{1} C_{1}-D_{2} C_{2} & D_{1}{ }^{2} C_{1}+D_{2}{ }^{2} C_{2}
\end{array}\right] \\
& \mathbf{K}_{\mathbf{v}}=\left[\begin{array}{cc}
K_{1}+K_{2} & D_{1} K_{1}-D_{2} K_{2} \\
D_{1} K_{1}-D_{2} K_{2} & D_{1}{ }^{2} K_{1}+D_{2}{ }^{2} K_{2}
\end{array}\right]
\end{aligned}
$$




$$
\begin{aligned}
& \mathbf{f}_{\mathbf{v}}=\left\{\begin{array}{c}
\sum_{i=1}^{2}\left(K_{i} w_{v, i}+C_{i} \dot{w}_{v, i}\right) \\
-\sum_{i=1}^{2}(-1)^{i} D_{i}\left(K_{i} w_{v, i}+C_{i} \dot{w}_{v, i}\right)
\end{array}\right\} \\
& \mathbf{M}_{g}=\left[\begin{array}{cc}
\mathbf{M}_{\mathbf{v}} & 0 \\
0 & \mathbf{M}_{\mathbf{b}}
\end{array}\right], \mathbf{C}_{\mathbf{g}}=\left[\begin{array}{cc}
\mathbf{C}_{\mathbf{v}} & \mathbf{C}_{\mathbf{v b}} \\
\mathbf{C}_{\mathbf{b v}} & \mathbf{C}_{\mathbf{b}}+\mathbf{C}_{\mathbf{b b}}
\end{array}\right], \mathbf{K}_{\mathbf{g}}=\left[\begin{array}{cc}
\mathbf{K}_{\mathbf{v}} & \mathbf{K}_{\mathbf{v b}} \\
\mathbf{K}_{\mathbf{b v}} & \mathbf{K}_{\mathbf{b}}+\mathbf{K}_{\mathbf{b b}}
\end{array}\right] \\
& \mathbf{C}_{\mathbf{b v}}=\left[-\mathbf{N}_{\mathbf{b}}\left[\begin{array}{cc}
C_{1} & D_{1} C_{1} \\
C_{2} & -D_{2} C_{2}
\end{array}\right]\right]_{n \times 2}, \quad \mathbf{C}_{\mathbf{v b}}=\mathbf{C}_{\mathbf{b v}}{ }^{\mathrm{T}} \\
& \mathbf{K}_{\mathbf{b v}}=\left[-\mathbf{N}_{\mathbf{b}}\left[\begin{array}{cc}
K_{1} & D_{1} K_{1} \\
K_{2} & -D_{2} K_{2}
\end{array}\right]\right]_{\mathbf{n} \times \mathbf{2}}, \quad \mathbf{K}_{\mathbf{v b}}=\mathbf{K}_{\mathbf{b v}}{ }^{\mathbf{T}} \\
& \mathbf{C}_{\mathbf{b b}}=\left[\mathbf{N}_{\mathbf{b}}\left[\mathbf{N}_{\mathbf{b}}\left[\begin{array}{cc}
C_{1} & 0 \\
0 & C_{2}
\end{array}\right]\right]^{T}\right]_{n \times n} \\
& \mathbf{K}_{\mathbf{b b}}=\left[\mathbf{N}_{\mathbf{b}}\left[\mathbf{N}_{\mathbf{b}}\left[\begin{array}{cc}
K_{1} & 0 \\
0 & K_{2}
\end{array}\right]\right]^{T}\right]_{n \times n} \\
& \mathbf{f}=\left\{\begin{array}{c}
\sum_{i=1}^{2}\left(K_{i} r_{i}+C_{i} \dot{r}_{i}\right) \\
-\sum_{i=1}^{2}(-1)^{i} D_{i}\left(K_{i} r_{i}+C_{i} \dot{r}_{i}\right) \\
\mathbf{N}_{\mathbf{b}}\left\{\begin{array}{l}
P_{1}-K_{1} r_{1}-C_{1} \dot{r}_{1} \\
P_{2}-K_{2} r_{2}-C_{2} \dot{r}_{2}
\end{array}\right\}
\end{array}\right\}_{(n+2) \times 1} \\
& \mathbf{N}_{\mathbf{b}}=\left[\begin{array}{cc}
0 & 0 \\
N_{1} & 0 \\
0 & N_{2} \\
0 & 0
\end{array}\right]_{n \times 2}
\end{aligned}
$$

The location matrix $\mathbf{N}_{\mathbf{b}}$ contains zero entries everywhere except the locations of the coordinates which correspond to the nodal displacements and rotations of the beam elements that the vehicle is in contact with. It should be noted that entries corresponding to the boundary conditions are also zero. The Hermitian shape function $N_{i}$ for the $i^{\text {th }}$ interaction force located on an element $j$ can be written in global coordinates as: 


$$
N_{i}=\left\{\begin{array}{c}
1-3\left(\frac{x_{i}-(j-1) l}{l}\right)^{2}+2\left(\frac{x_{i}-(j-1) l}{l}\right)^{3} \\
\left(x_{i}-(j-1) l\right)-\frac{2\left(x_{i}-(j-1) l\right)^{2}}{l}+\frac{\left(x_{i}-(j-1) l\right)^{3}}{l^{2}} \\
3\left(\frac{x_{i}-(j-1) l}{l}\right)^{2}-2\left(\frac{x_{i}-(j-1) l}{l}\right)^{3} \\
-\frac{\left(x_{i}-(j-1) l\right)^{2}}{l}+\frac{\left(x_{i}-(j-1) l\right)^{3}}{l^{2}}
\end{array}\right\}
$$

where $l$ is the length of the beam element and $(j-1) l \leq x_{i} \leq j l$.

\section{References}

1. Brownjohn JMW, Moyo P, Omenzetter P, et al. Lessons from monitoring the performance of highway bridges. Struct. Control Health Monit. 2005; 12(3-4): 227-244.

2. Farrar C and Worden K. An introduction to structural health monitoring. Philos. Trans. R. Soc. London, Ser. A 2007; 365: 303-315

3. Cunha A, Caetano E, Magalhães F, et al. Recent perspectives in dynamic testing and monitoring of bridges. Struct. Control Health Monit. 2013; 20(6): 853-877.

4. Farrar CR and Worden K. Structural Health Monitoring: A Machine Learning Perspective. Chichester, West Sussex, U.K.; Hoboken, N.J.: Wiley, 2013.

5. Doebling SW, Farrar CR and Prime MB. A summary review of vibration-based damage identification methods. Shock Vib. Digest 1998; 30(2): 91-105.

6. Sohn H, Farrar CR, Hemez FM, et al. A review of structural health monitoring literature: 1996-2001. Los Alamos National Laboratory Report LA-13976-MS, USA, 2003.

7. Carden EP and Fanning P. Vibration based condition monitoring: A review. Struct. Health Monit. 2004; 3(4): 355-377. 
8. Cerda F, Chen S, Bielak J, et al. Indirect Structural Health Monitoring of a Simplified LaboratoryScale Bridge Model. Smart Struct. Sys. 2014; 13(5): 849-868. doi:10.12989/sss.2014.13.5.849.

9. McGetrick PJ and Kim CW. An indirect bridge inspection method incorporating a wavelet-based damage indicator and pattern recognition. Proceedings of the 9th International Conference on Structural Dynamics, EURODYN 2014, 30 ${ }^{\text {th }}$ June $-2^{\text {nd }}$ July 2014, Porto, Portugal, paper no. 1217.

10. Yang YB, Lin CW and Yau JD. Extracting bridge frequencies from the dynamic response of a passing vehicle. J. Sound Vib. 2004; 272: 471-493.

11. Yang YB and Lin CW. Vehicle-bridge interaction dynamics and potential applications. J. Sound Vib. 2005; 284: 205-226.

12. McGetrick PJ, González A and OBrien EJ. Theoretical investigation of the use of a moving vehicle to identify bridge dynamic parameters. Insight 2009; 51(8): 433-438.

13. González A, OBrien EJ and McGetrick PJ. Detection of Bridge Dynamic Parameters Using an Instrumented Vehicle. In: Proceedings of the Fifth World Conference on Structural Control and Monitoring, Tokyo, Japan, 12-14 July 2010, paper no. 34.

14. Yang YB and Chang KC. Extracting the bridge frequencies indirectly from a passing vehicle: Parametric study. Eng. Struct. 2009b; 31(10): 2448-2459.

15. Lin CW and Yang YB. Use of a passing vehicle to scan the fundamental bridge frequencies. An experimental verification. Eng. Struct. 2005; 27: 1865-1878.

16. Oshima Y, Yamaguchi T, Kobayashi Y, et al. Eigenfrequency estimation for bridges using the response of a passing vehicle with excitation system. In: Proceedings of the Fourth International Conference on Bridge Maintenance, Safety and Management, (IABMAS2008), Seoul, Korea, 13-17 July 2008, pp. 3030-3037.

17. González A, Covián E and Madera J. Determination of Bridge Natural Frequencies Using a Moving Vehicle Instrumented with Accelerometers and GPS. In: Proceedings of the Ninth International 
Conference on Computational Structures Technology, Athens, Greece, 2-5 September 2008, paper no. 281.

18. Yang YB and Chang KC. Extraction of bridge frequencies from the dynamic response of a passing vehicle enhanced by the EMD technique. J. Sound Vib. 2009a; 322: 718-739.

19. Toshinami T, Kawatani $M$ and Kim CW. Feasibility investigation for identifying bridge's fundamental frequencies from vehicle vibrations. In: Proceedings of the Fifth International Conference on Bridge Maintenance, Safety and Management, (IABMAS2010), Philadelphia, USA, 11-15 July 2010, pp. 317-322.

20. Kim CW and Kawatani M. Challenge for a Drive-by Bridge Inspection. In: Proceedings of the 10th International Conference on Structural Safety and Reliability (ICOSSAR2009), Osaka, Japan, 13-17 September 2009, pp. 758-765.

21. Bu JQ, Law SS and Zhu XQ. Innovative bridge condition assessment from dynamic response of a passing vehicle. J. Eng. Mech. (ASCE) 2006; 132(12): 1372-1379.

22. MATLAB. The MathWorks, Inc., MATLAB, Version 7, USA; 2005. http://www.mathworks.com. 23. Kim CW, Kawatani $\mathrm{M}$ and Kim KB. Three-dimensional dynamic analysis for bridge-vehicle interaction with roadway roughness. Comput. Struct. 2005; 83: 1627-1645.

24. ISO 8608: Mechanical vibration - Road surface profiles - Reporting of Measured Data. International Organization for Standardization, 1995.

25. González A, OBrien EJ and McGetrick PJ. Identification of damping in a bridge using a moving instrumented vehicle. J. Sound Vib. 2012; 331(18): 4115-4131.

26. Clough RW and Penzien J. Dynamics of structures. 2nd ed. New York, USA: McGraw-Hill, 1993.

27. Frýba L. Vibration of Solids and Structures under Moving Loads. Groningen, the Netherlands: Noordhoff International Publishing, 1999. 
28. Chang KC, Kim CW and Borjigin S. Variability in bridge frequency induced by a parked vehicle. Smart Struct. Sys. 2014; 13(5): 755-773.

29. Yang YB, Cheng MC and Chang KC. Frequency variation in vehicle-bridge interaction systems. Int. J. Struct. Stab. Dyn. 2013; 13(2): 1350019. doi:10.1142/S0219455413500193.

30. Mottershead JE and Friswell MI. Model updating in structural dynamics: a survey. J. Sound Vib. 1993; 167(2): 347-375.

31. Friswell MI and Mottershead JE. Finite element model updating in structural dynamics. The Netherlands: Kluwer Academic Publishers, 1995, pp. 286.

32. Brownjohn JMW, Xia PQ, Hao H, et al. Civil structure condition assessment by FE model updating: methodology and case studies. Finite Elem. Anal. Des. 2001; 37(10): 761-775.

33. Xia PQ and Brownjohn, JMW. Residual stiffness assessment of structurally failed reinforced concrete structure by dynamic testing and finite element model updating. Exp. Mech. 2003; 43(4): 372-378.

34. Teughels A and De Roeck G. Structural damage identification of the highway bridge Z24 by FE model updating. J. Sound Vib. 2004; 278(3): 589-610.

35. Rubinstein RY and Kroese DP. The cross-entropy method: A unified approach to combinatorial optimization, monte-carlo simulation, and machine learning. New York, USA: Springer, 2004.

36. Henchi K, Fafard M, Talbot M, et al. An efficient algorithm for dynamic analysis of bridges under moving vehicles using a coupled modal and physical components approach. J. Sound Vib. 1998; 212(4): 663-683.

37. Kim CW and Kawatani M. Pseudo-static approach for damage identification of bridges based on coupling vibration with a moving vehicle. Struct. Infrastruct. Eng. 2008; 4(5): 371-379.

38. Deng L and Cai CS. Development of dynamic impact factor for performance evaluation of existing multi-girder concrete bridges. Eng. Struct. 2010; 32(1): 21-31. 
39. González A. Vehicle-bridge dynamic interaction using finite element modelling. In: David Moratal (ed.) Finite Element Analysis. Croatia: Sciyo, 2010, pp. 637-662.

40. Yang YB, Yau JD and Wu YS. Vehicle-Bridge Interaction Dynamics - With Applications to HighSpeed Railways. Singapore: World Scientific Publishing Co., 2004.

41. Bathe KJ and Wilson EL. Numerical methods in finite element analysis. Englewood Cliffs, N.J.: Prentice Hall, 1976.

42. Tedesco JW, McDougal WG and Ross CA. Structural Dynamics, Theory and Applications. Boston, USA: Addison-Wesley, 1999.

43. Weaver W and Johnston PR. Structural Dynamics by Finite Elements. UK: Prentice-Hall, 1987.

44. Memory TJ, Thambiratnam DP and Brameld GH. Free vibration analysis of bridges. Eng. Struct. 1995; 17(10): 705-713.

45. Walsh BJ and González A. Assessment of the Condition of a Beam Using a Static Loading Test. Key Eng. Mater. 2009; 413-414: 269-276.

46. de Boer PT, Kroese DP, Mannor S, et al. A Tutorial on the Cross-Entropy Method. Ann. Oper. Res. 2005; 134(1): 19-67.

47. Belay A, OBrien EJ and Kroese D. Truck fleet model for design and assessment of flexible pavements. J. Sound Vib. 2008; 311: 1161-1174.

48. Peeters B and De Roeck G. One-year monitoring of the Z 24-Bridge: environmental effects versus damage events. Earthquake Engng Struct. Dyn. 2001; 30: 149-171.

49. Xia Y, Hao H, Zanardo G and Deeks A. Long term vibration monitoring of an RC slab: Temperature and humidity effect. Eng. Struct. 2006; 28(3): 441-452. doi:10.1016/j.engstruct.2005.09.001

50. Sohn H. Effects of environmental and operational variability on structural health monitoring. Philos. Trans. R. Soc. London, Ser. A 2007; 365(1851): 539-60. doi:10.1098/rsta.2006.1935 
51. Liu C and DeWolf J. Effect of temperature on modal variability of a curved concrete bridge under ambient loads. J. Struct. Eng. 2007; 133(12): 1742-1751.

52. Reynders E, Wursten G and De Roeck G. Output-only structural health monitoring in changing environmental conditions by means of nonlinear system identification. Struct. Health Monit. 2013; 13(1): 82-93. doi:10.1177/1475921713502836 